\title{
Práticas Obstétricas Humanizadas X Resultados Perinatais
}

\author{
Amaral, Ana Carolina Bhering Alves do; Machado, Ana Carolina Barbosa; Aluani, \\ Erminda P.; Trindade, Ivani Cristina; Carvalho, Otávio; Souza, Pâmela \\ Hospital Geral de Itapevi — super.enf.cpn@hgi.org.br
}

O nascimento de um filho é um dos eventos mais importantes na vida de uma família, de uma rede social e, particularmente, de uma mulher. Práticas associadas, recomendadas e adotadas ao processo de nascimento são importantes para a saúde e para o bem estar da mulher e do recém-nascido. Assim sendo, faz-se necessário uma compreensão dos diferentes elementos envolvidos nestas práticas, que conduzam, dentre outros aspectos, ao entendimento dos componentes envolvidos na gênese do atual saber hegemônico em obstetrícia, para que a partir do conhecimento do velho se possa criar as condições para o surgimento do novo. As origens e razões pelas quais determinados procedimentos e rotinas vêm sendo mantidos, sem que se tenha estabelecido o grau de segurança para a mulher ou para o bebê, ou mesmo se trariam mais benefícios do que prejuízos à saúde dos usuários, é uma questão que ainda permanece sem resposta em determinadas instituições. Algumas "verdades" como a segurança do parto normal, associado a "epidemia de cesarianas" no Brasil e ao uso rotineiro de episiotomia e de ocitócitos expõe mulheres às chamadas "cascatas de intervenções" , aumentando a morbi-mortalidade perinatal. Acreditando nas práticas recomendadas pela Organização Mundial de Saúde, desenvolvemos este trabalho com o objetivo de apresentar os resultados perinatais obtidos com a adotação das paráticas humanizadas ofericidas ao processo de nascimento em um Hospital Geral localizado na Rota dos Bandeirantes no ano de 2013. o Hospital em destaque apresentou indicadores obstétricos e neonatais favoráveis, evidenciados pelos índices de asfixia neonatal abaixo do aceitável, pelo uso criterioso de episiotomia e amniotomia precoce pela equipe de enfermeiras obstetras responsáveis pela assistência ao parto, pela ausência do comprometimento do assoalho pélvico após o parto normal, pela taxa nula de tocotraumatismo materno e baixa frequência no uso de ocitócito e ocorrência de tocotraumatismo fetal. a interpretação destes achados nos levam a concluir que as evidências corroboraram com as recomendações e práticas recomendadas pela Organização Mundial de Saúde para a realização do parto com segurança, envolveram mudanças de paradigmas e culturas da equipe, nos levaram a acreditar incondicionalmente que o parto seguro é aqui.

Amaral, Ana Carolina Bhering Alves do; Machado, Ana Carolina Barbosa; Aluani, Erminda P.; Trindade, Ivani Cristina; Carvalho, Otávio; Souza, Pâmela. Práticas Obstétricas Humanizadas X Resultados Perinatais. In:

Anais do Congresso Internacional de Humanidades \& Humanização em Saúde [= Blucher Medical Proceedings, num.2, vol.1]. São Paulo: Editora Blucher, 2014. ISSN 2357-7282

DOI 10.5151/medpro-cihhs-10821 